\title{
Molecular cloning, expression, purification and functional characterization of an antifungal cyclophilin protein from Panax ginseng
}

\author{
HUI ZHANG ${ }^{1}$, JIAWEN WANG ${ }^{1}$, SHUAIJUN LI ${ }^{1}$, SIMING WANG ${ }^{1}$, \\ MEICHEN LIU ${ }^{1}$, WEINAN WANG ${ }^{2}$ and YU ZHAO $^{1}$ \\ ${ }^{1}$ Traditional Chinese Medicine and Biotechnology Research and Development Center; ${ }^{2}$ School of Pharmaceutical Sciences, \\ Changchun University of Traditional Chinese Medicine, Changchun, Jilin 130117, P.R. China
}

Received September 25, 2017; Accepted October 2, 2017

DOI: $10.3892 /$ br.2017.998

\begin{abstract}
Cyclophilins (CyPs), a member of peptidyl-prolyl cis-trans isomerases (PPIases), are ubiquitously distributed in organisms such as bacteria, yeast, plants and animals. CyPs have diverse biological functions, with some exhibiting antifungal and antiviral activities. In this study, Panax ginseng cyclophilin $(p g C y P)$, a novel gene encoding an antifungal protein from Panax ginseng, was cloned, and its protein product was expressed in Escherichia coli, and then fractionated by affinity chromatography. The open reading frame of the $p g C y P$ full-length coding sequence was found to encode a single-domain CyP-like protein of 174 amino residues with a calculated molecular weight of $18.7 \mathrm{kDa}$. The pGEX system was used to express pgCyP fused to glutathione S-transferase. After affinity purification, the protein showed a strong fungal resistance effect on Phytophthora cactorum. In addition, pgCyP showed high PPIase activity. To the best of our knowledge, the present study is the first successful effort to clone and characterize a CyP-like protein gene from Panax ginseng.
\end{abstract}

\section{Introduction}

Pathogenic fungi cause a wide range of damage in organisms, including in plants, humans and other animals. To protect

Correspondence to: Dr Yu Zhao, Traditional Chinese Medicine and Biotechnology Research and Development Center, Changchun University of Traditional Chinese Medicine, 1035 Boshuo Road, Changchun, Jilin 130117, P.R. China

E-mail: cnzhaoyu1972@126.com

Abbreviations: CyP, cyclophilin; PPIase, peptidyl-prolyl cis-trans isomerase; GST, glutathione S-transferase; PDA, potato dextrose agar; RT-PCR, reverse transcription-polymerase chain reaction; IPTG, isopropyl $\beta$-D-1-thiogalactopyranoside

Key words: antifungal activity, cyclophilin, expression and purification, Panax ginseng, peptidyl-prolyl cis-trans isomerase themselves against fungal pathogens, living organisms produce a myriad molecules. Different classes of antifungal proteins isolated from various plants include chitinases, cyclophilins (CyPs), defensins, lectins and lipid transfer proteins (1-7), all of which kill or suppress the infection of pathogenic microorganisms. In addition, the introduction of genes encoding these proteins into crop species has been found to confer enhanced resistance on the resulting transgenic lines (8).

CyPs, also known as immunophilins, peptidyl-prolyl cis-trans isomerases (PPIases) and cyclosporine A-binding proteins, are expressed in a variety of organisms (plants, yeast, fruit flies, parasites, rats and humans) (9) and exhibit high homology to one another. In plants, CyPs were first reported in 1990 with the isolation of CyP cDNA sequences from tomato, maize and oilseed rape (10). CyPs have endogenous PPIase activity that isomerizes the cis-trans conformation of imide linkage in substrates (11). Multiple CyP members in plants such as rice and Arabidopsis are associated with diverse functions and regulatory pathways related to their foldase, chaperoning, scaffolding and other (unknown) activities (12-15). Antifungal and antiviral activities of CyPs can relieve the multiple stresses exerted by fungi and viruses (16). CyP-like antifungal proteins have been isolated from black-eyed pea, mung bean, Chinese cabbage and chickpea $(4,17,18)$. The CyP of Chinese cabbage has been shown to have pronounced effects on a variety of fungal pathogens (17).

Plant CyPs have two isoforms that differ according to the number of domains. The first isoform possesses only a single PPIase domain, whereas the second type is composed of a catalytic PPIase domain plus either a leucine zipper domain at the amino end, a tetratricopeptide repeat domain at carboxyl end or another domain related to sub-cellular localization (19). Members of the subfamily comprising divergent CyPs have another loop containing the consensus sequence XXGKXLH, a conserved Glu and two invariable Cys residues (20). It was reported that the divergent loop can mediate protein-to-protein interactions or may be part of a P-loop or ATP-binding site formed by residues 42-GEKCIGKS-49 and 163-VVIAD-167 (21).

Panax ginseng is a Chinese traditional herb that is believed to have medicinal restorative properties (22). During growth, 
ginseng is exposed to various soil-borne pathogenic microorganisms, including fungi, bacteria and nematodes. However, the manner in which ginseng resists fungi, especially through its protein contents remains to be investigated. From ginseng transcriptome databases previously established (23), a Panax ginseng cyclophilin ( $\mathrm{pgCyP}$ ) of interest was identified since it was highly induced during the period in which plant is highly blight-prone. This observation suggested that pgCyP is involved in the anti-microorganism process.

On the basis of that finding, the $p g C y P$ gene was cloned in the present study and expressed in a bacterial host. We tagged pgCyP with 6xHis to its end to facilitate chromatography. We also enhanced its expression amount by applying the pGEX vector with glutathione S-transferase (GST). The recombinant pgCyP exhibited strong antifungal activity against Phytophthora cactorum and also possessed PPIase activity.

\section{Materials and methods}

Biological material. Five-year-old plants of ginseng (Panax ginseng C.A. Meyer) were harvested from Fusong County (Jinlin, China). The freshly collected material was prepared for gene cloning.

Phytopathogenic fungal species used in this study were Rhizoctonia solani and Cylindrocarpon destructans (Hyphomycetes); Phytophthora cactorum (Oomycetes); Fusarium solani, Alternaria panax and Botrytis cinerea (Fungi imperfecti); and Sclerotinia sp. (Discomycetes). All the fungal species were obtained from Jilin Agricultural University (Changchun, China).

Plasmid constructs. Total RNA was seperated from ginseng leaves. The $p g C y P$ gene was obtained by carrying out polymerase chain reaction (PCR) amplification from leaf cDNA with synthetic nucleotide primers. The PCR product was inserted into pMD18-T (Takara, Dalian, China). After digestion with BamHI and NotI, the generated DNA fragment was cloned in a pGEX-6p1 vector.

Expression of recombinant pgCyP. The recombinant plasmid was transformed into Escherichia coli BL21 (DE3) to express pgCyP $\mathrm{His}_{6}$. Transformed cells were cultured in Luria-Bertani medium supplemented with $50 \mu \mathrm{g} / \mathrm{ml}$ ampicillin at $37^{\circ} \mathrm{C}$ on a rotary shaker at $200 \mathrm{rpm}$. When the $\mathrm{OD}_{600}$ value of the cell culture reached $0.6-0.8$, protein overexpression was induced by the addition of isopropyl $\beta$-D-1-thiogalactopyranoside (IPTG) (Sigma-Aldrich, St. Louis, MO, USA) to a final concentration of $0.5 \mathrm{mM}$, and the culture was grown for a further $5 \mathrm{~h}$. Cells were harvested by centrifugation at $10,000 \mathrm{x} g$ for $2 \mathrm{~min}$. Protein expression levels were analyzed by SDS-PAGE and visualized with Coomassie Blue staining (Bio-Rad Laboratories, Inc., Hercules, CA, USA).

Isolation and purification of recombinant pgCyP. The transformed cell pellets were resuspended in wash buffer $[20 \mathrm{mM}$ Tris ( $\mathrm{pH} 8.0$ ), $100 \mathrm{mM} \mathrm{NaCl}$ and $3 \mathrm{M}$ urea]. After centrifugation, the cells were lysed in lysis buffer $[50 \mathrm{mM}$ Tris- $\mathrm{HCl}$, $1 \mathrm{mM}$ EDTA, $100 \mathrm{mM} \mathrm{NaCl}$ (pH 8.0), $0.13 \mathrm{mM}$ phenylmethylsulfonyl fluoride, $0.5 \mathrm{mg} / \mathrm{ml}$ lysozyme and $1.33 \mathrm{mg} / \mathrm{ml}$ sodium deoxycholate] and sonicated at $4^{\circ} \mathrm{C}$ for $30 \mathrm{~min}$. DNase I was then added to a concentration of 2,000 U/ml and the solution was incubated at $37^{\circ} \mathrm{C}$ with shaking at $200 \mathrm{rpm}$ for $1 \mathrm{~h}$. The lysate was then centrifuged at $10,000 \mathrm{x} \mathrm{g}$ for $20 \mathrm{~min}$ at $4^{\circ} \mathrm{C}$. The resulting inclusion bodies were washed twice with a solution consisting of $50 \mathrm{mM}$ Tris, $100 \mathrm{mM} \mathrm{NaCl}$, $2 \mathrm{M}$ urea, $0.5 \%$ Triton-X and $10 \mathrm{mM}$ EDTA at $\mathrm{pH}$ 8.0. The washed inclusion bodies were dissolved by stirring for $1 \mathrm{~h}$ in extraction buffer [1.5\% sarkosyl, $25 \mathrm{mM}$ triethanolamine amine and $1 \mathrm{mM}$ EDTA ( $\mathrm{pH} \mathrm{8.0)]} \mathrm{at} 4^{\circ} \mathrm{C}$. The solubilized inclusion bodies were centrifuged at $10,000 \mathrm{x} \mathrm{g}$ for $10 \mathrm{~min}$ at $4^{\circ} \mathrm{C}$ and then refolded by dialysis in binding buffer $[10 \mathrm{mM}$ $\mathrm{NaH}_{2} \mathrm{PO}_{4} \cdot 2 \mathrm{H}_{2} \mathrm{O}, 10 \mathrm{mM} \mathrm{Na} \mathrm{HPO}_{4} \cdot 12 \mathrm{H}_{2} \mathrm{O}(\mathrm{pH} 7.8), 150 \mathrm{mM}$ $\mathrm{NaCl}$ and $10 \mathrm{mM}$ imidazole]. The refolded protein was purified by Ni-chelating Sepharose Fast Flow chromatography (GE Healthcare Bio-Sciences AB, Uppsala, Sweden). The adsorbed proteins were eluted with elution buffer containing $100 \mathrm{mM}$ imidazole. Eluates were pooled together and the samples were renatured on a Sephadex G-25 column. Protein concentrations were determined by the Bradford Protein Assay kit (Tiangen Biotech (Beijing) Co., Ltd., Beijing, China).

PPIase activity assay. A mixture of the following components was incubated on ice for $10 \mathrm{~min}$ : $930 \mu \mathrm{l}$ Assay Buffer [50 mM HEPES and $100 \mathrm{mM} \mathrm{NaCl}(\mathrm{pH} 7.8)$ ], $30 \mu \mathrm{l}$ of $200 \mu \mathrm{M} \alpha$-chymotrypsin (Sigma-Aldrich) and either $10 \mu \mathrm{l}$ of GST-pgCyP-His ${ }_{6}(1 \mu \mathrm{M})$ or the GST $(1 \mu \mathrm{M})$ negative control. Each sample was placed in a spectrophotometer (Thermo Fisher Scientific, Waltham, MA, USA), which was pre-cooled to $8^{\circ} \mathrm{C}$. After the addition of $30 \mu \mathrm{l}$ of $7.8 \mathrm{mM}$ Suc-Ala-Ala-Pro-Phe-NA (Sigma-Aldrich), absorbance at $390 \mathrm{~nm}$ was immediately recorded every second for $5 \mathrm{~min}$ at $8^{\circ} \mathrm{C}$.

pgCyP antifungal activity. GST-pgCyP-His ${ }_{6}$ and GST protein were tested for possession of antifungal activity. Fungi were grown in potato dextrose agar (PDA) for $48 \mathrm{~h}$ at $28^{\circ} \mathrm{C}$. The fungi were then spread onto PDA plates. Sterilized blank paper disks were placed on the plates and dotted with an aliquot of protein at different concentrations. The plates were incubated and monitored for up to 3 days. To determine the $\mathrm{IC}_{50}$ of proteins against various fungal pathogens, the fungal spores were collected and placed in 96-well microtiter plates. Recombinant $\operatorname{pgCyP}(20 \mu \mathrm{l})$ or the negative control was then added to each well. After $12-36 \mathrm{~h}$ of incubation at $28^{\circ} \mathrm{C}$, fungal growth was evaluated microscopically. The turbidity of each well was also measured by recording absorbance at $595 \mathrm{~nm}$ using a microtiter reader (Emax, Molecular Devices, Sunnyvale, CA, USA).

Sequence accession number. The nucleotide sequence of pgCyP in the present study has an accession no. KX034081 in GenBank.

\section{Results}

Cloning and sequence analysis of pgCyP in ginseng. As shown in Fig. 1A (lane 3), pgCyP cDNA was successfully generated by reverse transcription-polymerase chain reaction (RT-PCR) amplification from cDNA of ginseng leaves. The corresponding nucleotide sequence, consisting of $525 \mathrm{bp}$, was predicted to be 174 a.a. in length, as well as a theoretical isoelectric point 
A

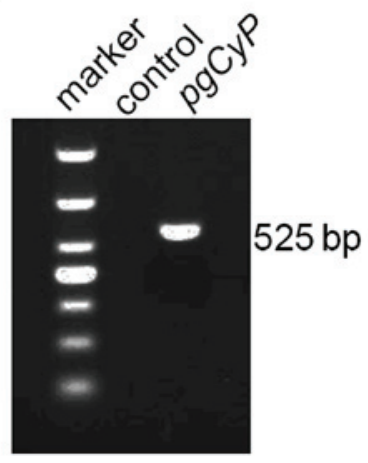

B

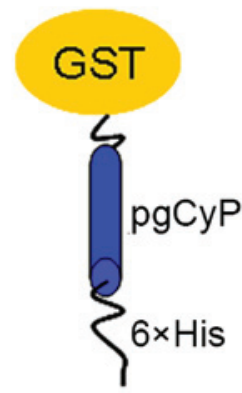

C

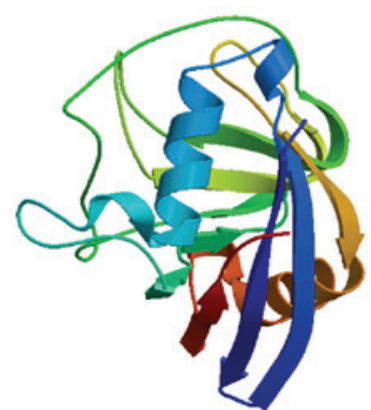

\section{D}
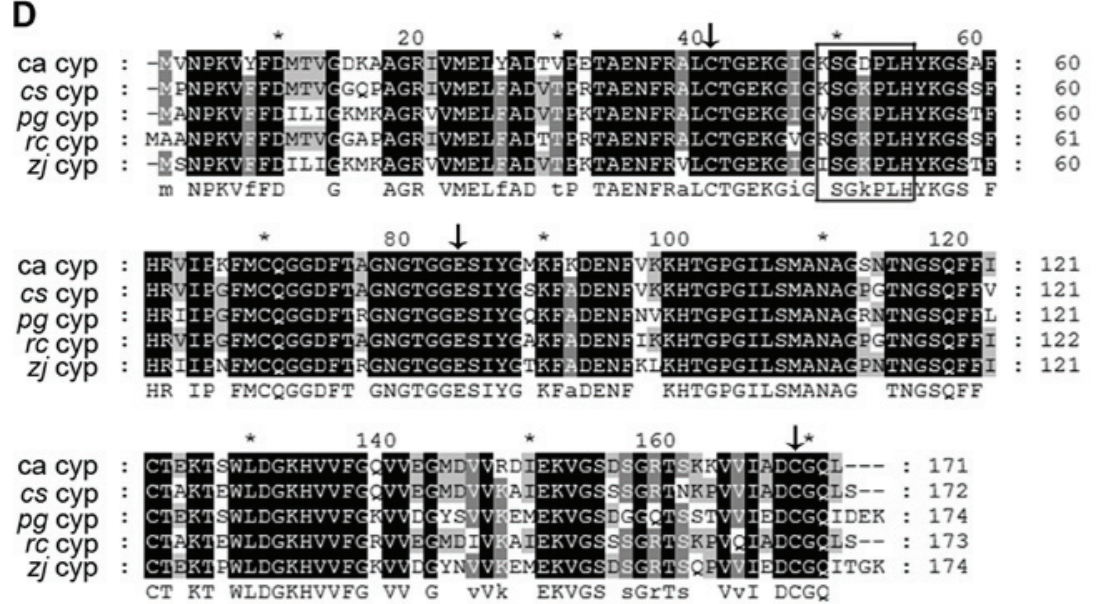

Figure 1. Detection of the $p g C y P$ gene transcript and sequence analysis. (A) PCR amplification of pgCyP by RT-PCR from total mRNA of ginseng leaves Marker refers to the DNA molecular marker, while control is the mock-DNA negative control. (B) Schematic representation of constructs of GST-pgCyP-His ${ }_{6}$. (C) Predicted 3D structure model of pgCyP. The 3D structure model was predicted using the SWISS-MODEL server. (D) Alignment of the amino acid sequences of CyPs of Panax ginseng and other species. Residues comprising the divergent loop are shown in a black box, whereas the conserved Cys residues (Cys-40 and Cys-168) and Glu (Glu-83) are indicated with black arrows. pgCyP, Panax ginseng cyclophilin; PCR, polymerase chain reaction; GST, glutathione S-transferase; RT-PCR, reverse transcription-polymerase chain reaction; CyP, cyclophilin; ca, Chinese cabbage; cs, Citrus sinensis; zj, Ziziphus jujuba; rc, Ricinus communis.

of 7.67 and a molecular weight of $18.7 \mathrm{kDa}$. As it lacked a transit peptide, this predicted protein was probably localized in the cytosol (24). The pgCyP protein contained a PPIase domain and a divergent loop (48-VSGKPLH-54). Two CyPs (positioned at 40 and 168) as well as a Glu (positioned at 83) were conservatively kept similar to the other members in the CyPs family. The predicted secondary structure of pgCyP comprised $6.32 \%$ $\alpha$ helices, $21.26 \%$ extended strands and $72.42 \%$ random coils. On the basis of protein sequence alignment, pgCyP was closely associated with Ziziphus jujuba CyP, Citrus sinensis CyP19-3 and Ricinus communis CyP proteins. pgCyP shares 90\% identity with its homolog in Ziziphus jujuba (Fig. 1D).

In the phylogenetic tree of CyP-like proteins shown in Fig. 2, pgCyP may be classified, as expected, into the clade of CyP proteins from dicot species, where it is most closely related to Ziziphus jujuba belonging to the same family. A 3D pgCyP model was created through primary protein sequence (25) using the SWISS-MODEL server (Fig. 1C).

Construction, expression and purification of GST-pgCyP-His . cDNA of the pgCyP isolated from this study, which differs from the pgCyP previously reported (23), and possibly belongs to a different ginseng CyP subfamily, was cloned into vector pMD18-T. The resulting plasmid was then digested with

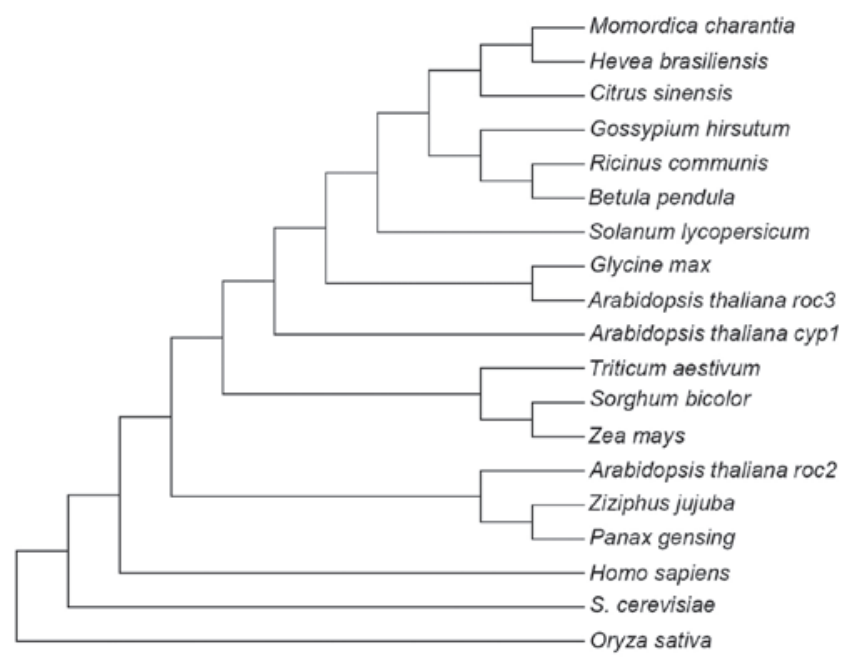

Figure 2. Phylogenetic tree of cyclophilin proteins from plants, humans and yeast. The software program MEGA5 was used for alignment of amino acid sequences and to generate a phylogenetic tree based on the neighbor-joining method.

BamHI and NotI. After target fragments were cloned into pGEX-6p1, the protein were carrying a tandem His tag and GST at both ends (Fig. 1B). 


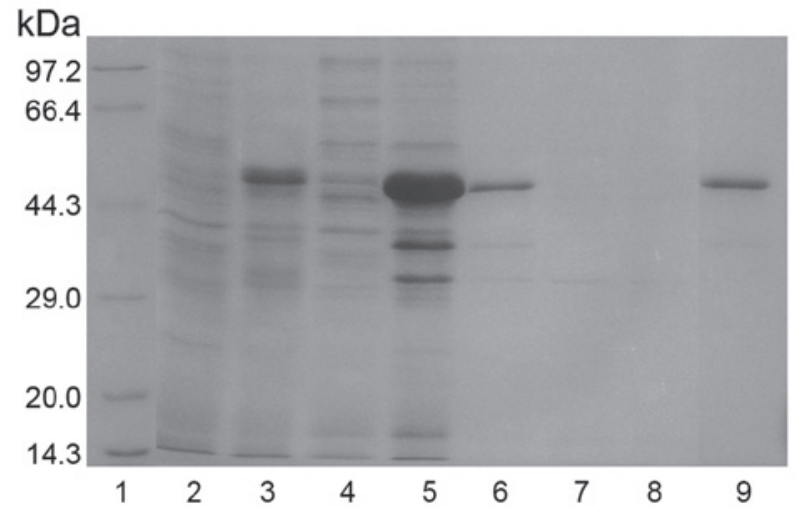

Figure 3. Expression, purification and refolding of GST-pgCyP-His ${ }_{6}$. Samples collected after purification of GST-pgCyP-His ${ }_{6}$ were analyzed by sodium dodecyl sulfate-polyacrylamide gel electrophoresis with Coomassie Brilliant Blue staining. Lane 1, marker; lane 2, sample before IPTG induction; lane 3 , sample subjected to IPTG induction; lane 4, soluble-protein fraction; lane 5, insoluble-protein fraction; lane 6, solubilized denatured insoluble-protein fraction; lane 7, purification flow-through fraction; lane 8, purification wash fraction; lane 9, purification elution fraction with $100 \mathrm{mM}$ imidazole. GST, glutathione S-transferase; pgCyP, Panax ginseng cyclophilin; IPTG, isopropyl $\beta$-D-1-thiogalactopyranoside.

Escherichia coli BL21 (DE3) competent cells were transformed with the pGEX-6p1/pgCyP-His ${ }_{6}$ plasmid. Overexpression of recombinant protein was induced at different IPTG concentrations for different lengths of time. The optimal IPTG concentration and induction time was $0.5 \mathrm{mM}$ and $5 \mathrm{~h}$, respectively. The induced protein was resolved in SDS-PAGE. As expected, a protein bank of $46 \mathrm{kDa}$ was evident (Fig. 3). Moreover, the analysis indicated GST-pgCyP-His ${ }_{6}$ present as inclusion bodies (Fig. 3).

After solubilizing the inclusion bodies in extraction buffer, pgCyP was purified using Ni-NTA affinity chromatography as described in Materials and methods. The target protein with His tag was fractionated with $100 \mathrm{mM}$ imidazole. GST-pgCyP-His ${ }_{6}$ was confirmed in SDS-Page (lane 9, Fig. 3).

In vitro antifungal activity of $p g C y P$. After purification and renaturation, the recombinant protein was tested for its ability to inhibit fungal growth in vitro. Pathogenic fungus included Sclerotinia sp., R. solani, P. cactorum, F. solani, C. destructans, $A$. panax and $B$. cinerea. The fusion protein at concentrations of 1.28 and $2.14 \mu \mathrm{M}$ had pronounced effects on the growth of P. cactorum (Fig. 4A), but had no effect on the growth of the other fungi. The $\mathrm{IC}_{50}$ of pgCyP against $P$. cactorum, was $2.55 \mu \mathrm{M}$ (Fig. 4B). GST, as a negative control, was inactive. Hereby we demonstrate in vitro resistance activity against fungi of pgCyP.

PPIase activity of recombinant pgCyP. CyPs are PPIases. In the present study, we showed $\mathrm{pgCyP}$ has PPIase activity. $\mathrm{PgCyP}$ is capable of accelerating isomerization of imide between the Ala and Pro peptide bonds in contrast to spontaneous inter-conversion in the negative control. GST protein, the control, had no isomerize activity.

\section{Discussion}

Plant diseases are a major concern in the production of agricultural crops and medicinal herbs. Although an increasing
A

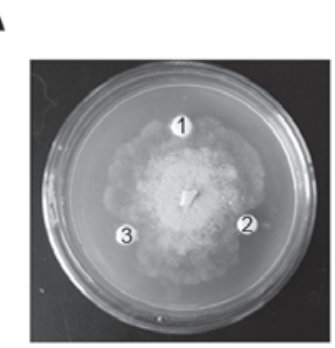

B

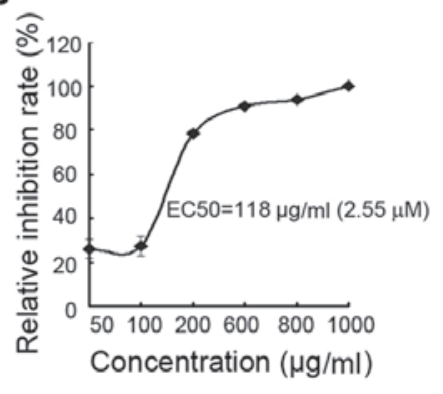

C

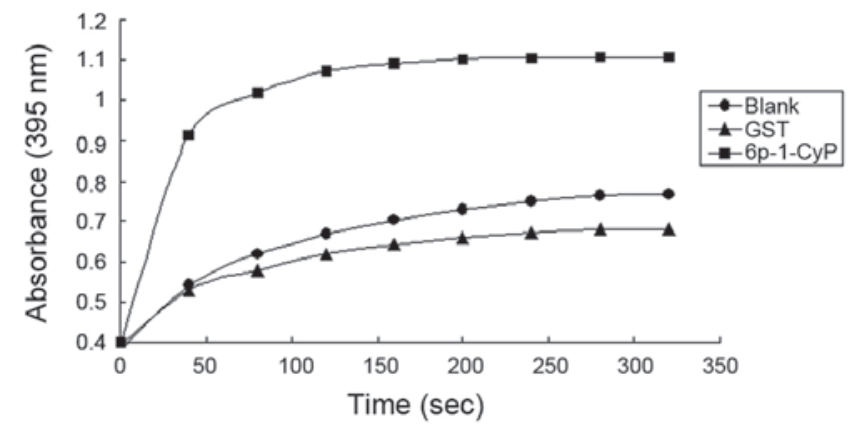

Figure 4. Antifungal activity and peptidyl-prolyl cis-trans isomerase activity of pgCyP. (A) Antifungal activity of purified pgCyP and GST protein tested against Phytophthora cactorum at concentrations of $2.14 \mu \mathrm{M}(\mathrm{GST}), 1.28 \mu \mathrm{M}$ (pgCyP) and $2.14 \mu \mathrm{M}$ (pgCyP). (B) Growth inhibition of fungal pathogen by purified pgCyP. (C) Spectrophotometric assay performed with $\mathrm{pgCyP}$ or GST or in the absence of the two proteins. The graph is representative of at least three independent experiments. pgCyP, Panax ginseng cyclophilin; GST, glutathione S-transferase.

number of antimicrobial peptides have been isolated from plants, there is little research on anti-microorganism proteins of ginseng. In the present study, we cloned and isolated a ginseng CyP protein. PgCyP contains an ORF of $525 \mathrm{bp}$ encoding 174 a.a. Ginseng blight is very prevalent during the rainy season (July to September), and our transcription expression level analysis revealed that CyP has a high expression in roots during the same period. This finding suggests a relationship between $\mathrm{pgCyP}$ expression and ginseng blight. In the antifungal test, pgCyP exhibited strong antifungal activity at micromolar concentrations against $P$. cactorum.

The expression vectors PET26b, PET28a and pRSET B were used; however, they failed to express pgCyP. GST, a chaperone for protein folding, is frequently selected to help isolation of soluble protein (26). However, use of GST-fusion system for insoluble GST-fusion protein isolation remains challenging (27). Ni-NTA affinity chromatography was effective, and the one-step method was used to isolate target proteins with His tag. Using this method, we were able to obtain pure GST-fused protein. We then attempted to hydrolyze the GST domain. Following protease treatment, the incised protein was unstable and rapidly degraded. Consequently, the GST tag was retained while performing the antifungal activity tests.

The functional properties of the generated fusion protein suggest pgCyP has PPIase activity. Taken together, our results provide evidence that $\mathrm{pgCyP}$ has antifungal activity. Previous findings have indicated that the $\mathrm{CyP}$ protein of Chinese cabbage has antifungal activity against $B$. cinerea, $T$. harzianum, $T$. viride, $R$. solani, F. solani and F. oxysporum (17). In the 
present study, however, pgCyP affected $P$. cactorum, growth only, with no activity observed against $R$. solani, $F$. solani or B. cinerea. pgCyP shares $78 \%$ identity with its homolog in Chinese cabbage. Thus, the divergent pattern of antifungal activity observed between the two homologous proteins may be related to differences in amino acid sequences. We aim to investigate the antifungal spectrum of $\mathrm{pgCyP}$ in a future study.

In conclusion, in this study, we carried out the successful heterologous expression, purification and characterization of $\mathrm{pgCyP}$ and investigated its structure and function. While CyPs are reported to be involved in biotic stress response, their exact functions remain to be identified. To demonstrate the possible molecular functions executed, identification of its downstream substrates is needed. Transgenic plants expressing the $p g C y P$ gene may facilitate revealing the physiological functions in the future.

\section{Acknowledgements}

This study was supported by grants from the National Natural Science Foundation of China (nos. 81373937, 81503212 and 81503324) and Jilin Scientific and Technological Development Program (no. 20140520042JH).

\section{References}

1. Kawase T, Yokokawa S, Saito A, Fujii T, Nikaidou N, Miyashita $\mathrm{K}$ and Watanabe T: Comparison of enzymatic and antifungal properties between family 18 and 19 chitinases from S. coelicolor A3(2). Biosci Biotechnol Biochem 70: 988-998, 2006.

2. Sattayasai N, Sudmoon R, Nuchadomrong S, Chaveerach A, Kuehnle AR, Mudalige-Jayawickrama RG and Bunyatratchata W: Dendrobium findleyanum agglutinin: Production, localization, anti-fungal activity and gene characterization. Plant Cell Rep 28: 1243-1252, 2009.

3. Wong JH and Ng TB: Sesquin, a potent defensin-like antimicrobial peptide from ground beans with inhibitory activities toward tumor cells and HIV-1 reverse transcriptase. Peptides 26 1120-1126, 2005.

4. Ye XY and Ng TB: Isolation of unguilin, a cyclophilin-like protein with anti-mitogenic, antiviral, and antifungal activities, from black-eyed pea. J Protein Chem 20: 353-359, 2001.

5. Lin P, Xia L and $\mathrm{Ng}$ TB: First isolation of an antifungal lipid transfer peptide from seeds of a Brassica species. Peptides 28: 1514-1519, 2007

6. Wang SY, Gong YS and Zhou JJ: Chromatographic isolation and characterization of a novel peroxidase from large lima legumes. J Food Sci 74: C193-C198, 2009.

7. Pelegrini PB, Noronha EF, Muniz MA, Vasconcelos IM, Chiarello MD, Oliveira JT and Franco OL: An antifungal peptide from passion fruit (Passiflora edulis) seeds with similarities to $2 \mathrm{~S}$ albumin proteins. Biochim Biophys Acta 1764: 1141-1146 2006.

8. Fritig B, Heitz T and Legrand M: Antimicrobial proteins in induced plant defense. Curr Opin Immunol 10: 16-22, 1998.

9. Galat A: Variations of sequences and amino acid compositions of proteins that sustain their biological functions: An analysis of the cyclophilin family of proteins. Arch Biochem Biophys 371: 149-162, 1999.
10. Gasser CS, Gunning DA, Budelier KA and Brown SM: Structure and expression of cytosolic cyclophilin/peptidyl-prolyl cis-trans isomerase of higher plants and production of active tomato cyclophilin in Escherichia coli. Proc Natl Acad Sci USA 87: 9519-9523, 1990.

11. Fischer G, Bang H and Mech C: Determination of enzymatic catalysis for the cis-trans-isomerization of peptide binding in proline-containing peptides. Biomed Biochim Acta 43: 1101-1111, 1984 (In German).

12. Kumari S, Roy S, Singh P, Singla-Pareek SL and Pareek A: Cyclophilins: Proteins in search of function. Plant Signal Behav 8: e22734, 2013.

13. Fu A, He Z, Cho HS, Lima A, Buchanan BB and Luan S: A chloroplast cyclophilin functions in the assembly and maintenance of photosystem II in Arabidopsis thaliana. Proc Natl Acad Sci USA 104: 15947-15952, 2007.

14. Ahn JC, Kim DW, You YN, Seok MS, Park JM, Hwang H, Kim BG, Luan S, Park HS and Cho HS: Classification of rice (Oryza sativa L. Japonica nipponbare) immunophilins (FKBPs, CYPs) and expression patterns under water stress. BMC Plant Biol 10: 253, 2010.

15. Kumari S, Singh P, Singla-Pareek SL and Pareek A: Heterologous expression of a salinity and developmentally regulated rice cyclophilin gene (OsCyp2) in E. coli and S. cerevisiae confers tolerance towards multiple abiotic stresses. Mol Biotechnol 42: 195-204, 2009.

16. Wong JH, Ng TB, Cheung RC, Ye XJ, Wang HX, Lam SK, Lin P, Chan YS, Fang EF, Ngai PH, et al: Proteins with antifungal properties and other medicinal applications from plants and mushrooms. Appl Microbiol Biotechnol 87: 1221-1235, 2010.

17. Lee JR, Park SC, Kim JY, Lee SS, Park Y, Cheong GW, Hahm KS and Lee SY: Molecular and functional characterization of a cyclophilin with antifungal activity from Chinese cabbage. Biochem Biophys Res Commun 353: 672-678, 2007.

18. Ye XY and $\mathrm{Ng}$ TB: Isolation of a new cyclophilin-like protein from chickpeas with mitogenic, antifungal and anti-HIV-1 reverse transcriptase activities. Life Sci 70: 1129-1138, 2002.

19. Romano PG, Horton P and Gray JE: The Arabidopsis cyclophilin gene family. Plant Physiol 134: 1268-1282, 2004.

20. Peterson MR, Hall DR, Berriman M, Nunes JA, Leonard GA, Fairlamb AH and Hunter WN: The three-dimensional structure of a Plasmodium falciparum cyclophilin in complex with the potent anti-malarial cyclosporin A. J Mol Biol 298: 123-133, 2000.

21. Dornan J, Page AP, Taylor P, Wu S, Winter AD, Husi H and Walkinshaw MD: Biochemical and structural characterization of a divergent loop cyclophilin from Caenorhabditis elegans. J Biol Chem 274: 34877-34883, 1999.

22. Arushanian EB and Beǐer EV: Participation of pineal gland in antistressor activity of adaptogenic drugs. Eksp Klin Farmakol 78: 9-12, 2015 (In Russian).

23. Liu J, Wang Q, Sun M, Zhu L, Yang M and Zhao Y: Selection of reference genes for quantitative real-time PCR normalization in Panax ginseng at different stages of growth and in different organs. PLoS One 9: e112177, 2014.

24. Wang P and Heitman J: The cyclophilins. Genome Biol 6: 226, 2005.

25. Campos BM, Sforça ML, Ambrosio AL, Domingues MN, Brasil de Souza TA, Barbosa JA, Paes Leme AF, Perez CA, Whittaker SB, Murakami MT, et al: A redox 2-Cys mechanism regulates the catalytic activity of divergent cyclophilins. Plant Physiol 162: 1311-1323, 2013.

26. Harper S and Speicher DW: Purification of proteins fused to glutathione S-transferase. Methods Mol Biol 681: 259-280, 2011.

27. Park DW, Kim SS, Nam MK, Kim GY, Kim J and Rhim H: Improved recovery of active GST-fusion proteins from insoluble aggregates: Solubilization and purification conditions using PKM2 and HtrA2 as model proteins. BMB Rep 44: 279-284, 2011. 